\title{
Editorial
}

\section{Health care and health innovation in Europe: regulating for public benefit or for commercial profit?}

\author{
AMANDA WARREN-JONES* \\ Director, SIBLE - Health; Senior Law Lecturer, Sheffield University School of Law, Bartolome House, Sheffield, UK
}

Regulating health care is an activity which is traditionally justified by the need to achieve public benefits, but is increasingly expected to achieve benefits in global, European and domestic markets. This shift in expectations is evident in recent global reports (such as the 2013 WHO, WIPO and WTO report on Promoting Access to Medical Technologies and Innovation) urging policy-makers to adopt a regulatory overview which appreciates the nexus between health innovation, health needs and global trade. It is also overtly identified in initiatives adopted by individual EU Member States which regard health care provision and health innovation as a source of wealth and economic efficiency. ${ }^{1}$ Perhaps more pressingly, a market-based approach to health care threatens to become absolute if the Transatlantic Trade and Investment Partnership precipitates the privatisation of the remaining publicly provided services.

This change in regulatory rationale raises important issues about the degree to which health care provision can secure public benefits and respect individual rights, while actively seeking market benefits such as cost-efficiencies and private profits. Yet, the dialectic between the interests of users of health care products and services, and the interests of health care providers and producers is inherently lost by contributions to the literature adopting divergent analytical perspectives. This journal exemplifies the diversity of existing literature through five papers which all speak to entirely different analytical regulatory perspectives and relate to fundamentally different contexts of health care, but each adds to a collective understanding of the dynamic between public and private interests. Understanding

\footnotetext{
*Correspondence to: Dr Amanda Warren-Jones, Director, SIBLE - Health; Senior Law Lecturer, Sheffield University School of Law, Bartolome House, Winter Street, Sheffield, S3 7ND, UK. Email: a.warren-jones@sheffield.ac.uk

1 For example, in the United Kingdom the Department of Health's 2011 Report on Innovation, Health and Wealth: Accelerating Adoption and Diffusion in the NHS and the subsequent adoption of 15 Academic Health Science Networks tasked with driving innovation into health care and securing its proliferation exemplify regulating health care as a market. Since then the Health and Social Care Information Centre innovation scorecards and heat maps have supplemented the Technology Appraisals conducted by the National Institute for Health and Care Excellence, to monitor and promote the take up of specific health innovations.
} 
how important a contribution to existing literature this convergence is, begins from an appreciation of how disparate the analytical landscape is currently understood to be.

Even narrowed to interest-based perspectives, regulating health care can be considered to involve two direct interest relationships: the public relative to regulators; and industry relative to regulators. ${ }^{2}$ These require further exploration.

There has been considerable and prolonged debate about the nature of the public interest. In the middle of the 20th century five interpretations were identified, complying with majority consensus, overriding opinion, moral rights, competitive compromise, or the presence of an x-factor (Sorauf, 1957). A more contemporary understanding derives from rights-based, moral rights, market-based, or deliberative approaches (Hantke-Domas, 2003; Prosser, 2006; Brownsword and Goodwin, 2012; Gutmann and Thompson, 2004, respectively). Contextualised within a traditional interpretation in which public interests are those understood by regulators, the public are considered to be both a motivating force for regulation and as a rationalising basis underpinning general regulatory policies (Feintuck, 2004). For example, the public interest is the motivating force behind policies formulated to 'choice' or the 'expert patient' (Busfield, 2010). Alternatively, the public are invoked as the explanatory basis of regulatory oversight even where no public consultation has occurred (e.g. European Commission, 2008). A contemporary governance-based understanding of regulation extends this meaning of the public interest beyond this theoretical involvement which is merely channelled through the regulators' understanding. Instead, the public interest democratises regulation by including overt public involvement and this is evidenced through the rise of patient groups as stakeholders actively shaping regulation (e.g. European Commission, 2005). This level of public inclusion is utilised as evidence of a changing balance of interests between the public and regulators, with some commentators advocating further development towards a collaborative governance model which truly democratically regulates for the people and with the people (Sirianni, 2009; Donahue and Zeckhauser, 2011).

Conversely, interest group theories consider industry-regulator relationships and this is split between those believing that industry is the dominant partner and those believing that regulators adhere to their own agendas. Within the first camp, the belief is that industry submits to regulation only where competition is disrupted by market failure and the group - in this case industry - is prompted to capture the regulator in order to subvert its efforts to achieve industry benefits (Bernstein, 1955; Jackson, 2012). In consequence, industry is able to dictate policy and regulatory decision-making and, even though the incorporation of public interest groups can yield additional benefits, the regulator remains captive to industry interests (Ayres and Braithwaite, 1991; Carpenter and Moss, 2014).

2 Regulator is broadly interpreted as bodies empowered by governments and supra-national organisations. 
Within the second camp are those who believe that regulators follow their own private interests, for example being motivated to regulate to maximise their utility or wealth (Stigler, 1971; Posner, 1974; Drahos, 2004). Others believe regulators are politically or institutionally motivated by self-interest, for example being motivated to control industry because it yields democratic benefits from votes or the availability of other administrative benefits (Peltzman, 1976, 1984; Becker, 1986; Ogus, 2004). Straddling these two camps is corporate bias, which builds from a socio-political basis to argue that regulators satisfy their own interests by actively competing with each other for industry 'business' (Lewis and Abraham, 2001; Davis and Abraham, 2013).

Recent additions to regulatory theory include an assessment of regulators as ignoring both public and industry interests and being motivated instead not by self-interest, but by the need to explain themselves relative to the roles they are expected to perform. It follows that regulators' institutional aims and policy objectives prompt regulators to behave in predictable way, but in consequence benefits accrue to industry and/or the public as only an incidental by-product of the regulator's commitment to justifying their own actions (Warren-Jones, 2016).

It is clear that even this narrow theoretical landscape revolves around diverse considerations of the public interest on one hand and of private interests concerned with market failure on the other. This divide is maintained with ethical theory normatively considering the public interest, and regulatory theory being descriptively applied to private interests from economic perspectives. However, in combination these debates represent a continuum of public interests (as users and payers of health care services and products) relative to private interests (as providers and producers of health care services and products). From this overarching perspective, public and private interests are inherently intermingled in ways that transcend artificial theoretical divides. In other words, the public collectively and individually - industry and regulators are all interested in a fair share of ethical and economic interests. In addition, once that share of interests has been identified, all parties have an inherent interest in understanding how sustainable the benefits are, or whether they require continual review over time. It is to this deeper understanding of regulation as sustainable interest sharing that all of the papers contribute.

Chris Newdick's article sets the tone by mapping the polarised debates in political, ethical and medical law discourses to juxtapose individual autonomy against the public interest, the requirements for civic responsibility and the economic realities of public health care provision. As such his paper recognises that protecting individual interests above the collective ethical interests of the public and the economics of health care provision results in unsustainable regulation. Instead, regulation must be seen within the context of all interests, raising a case for addressing inequalities by imposing mechanisms on all those complicit in the unsustainable behaviour. This argues that the sustainability of health care provision imposes responsibility on regulators to 'trade off' both the 
ethical freedoms of the individual and the commercial freedoms of industry in favour of the public interest in having health care available to everyone all the time. As such, his paper embeds key issues around which these interrelationships revolve: the individual interest in autonomy, particularly in terms of consent; public trust in regulators and the focus on regulators as primarily responsible for mediating interests; and the sustainability of behaviours.

The issue of individual interests in autonomy is taken up most directly by Jean $\mathrm{McHale's} \mathrm{paper,} \mathrm{exploring} \mathrm{the} \mathrm{judicial} \mathrm{change} \mathrm{in} \mathrm{practice} \mathrm{represented} \mathrm{by} \mathrm{the}$ decision in the UK Supreme Court in Montgomery $v$ Lanarkshire. ${ }^{3}$ The position of Newdick's paper is that - in regulating everyday behaviours - autonomy should be put into abeyance to public interests and sustainability of health care provision, but the Supreme Court have adopted the opposite approach in ruling on health care treatment. The Supreme Court changed the understanding in medical practice that the expertise of professionals dictates the level of information required for consent to treatment (putting provider interests ahead of users), instead placing control in the patients' hands in deference to their autonomy and their human rights (putting individual users' interests ahead of either collective public interests or provider interests). In light of this decision, McHale argues that participants in medical research - irrespective of whether they are obtaining a therapeutic value in the course of the trial or not - should be given the same level of respect for their individual rights. This is not only because there should be parity between participants and patients, but also because participants contribute to the public interest in health care innovation. In other words, from an ethical perspective the gain in public interest benefit warrants the priority being given to individual interests over all other interests.

However, consent is also touched upon in Amanda Warren-Jones' paper, arguing that - from a commercial perspective - shifting the responsibility for identifying the quality of treatments and medical products onto sick patients' is ill-advised. The effect of reducing the involvement of medical professionals in vouching for the credibility of health care instead invites the lacuna to be filled by industry and patient groups furthering their own agendas, rather than supporting either individual patient-users or the public interest in delivering excellent innovative treatments. Collectively, these papers identify reason to have a more comprehensive debate about the nature of consent, especially in light of recent initiatives to introduce individual control of consent through a dynamic system (Kaye et al., 2015).

Embedded within many of the papers is the issue of trust in regulators as protectors of the public good. For Newdick the issue of trust is intrinsic to the public health ethics presumption that health inequality is a social injustice that the regulator is intended to resolve. The failure to correct it either by changing social inequality or redistributing benefits therefore breaches this trust.

3 Montgomery $v$ Landarkshire Health Board (Scotland) [2015] UKSC 11. 
Graham Dutfield's paper appears to be entirely unrelated in considering the pharmaceutical privilege that permits old innovation to be claimed as new health care products and attracting patent rights. Yet, the commonality is that Dutfield's paper considers the balance between the public interest in having access to innovative medicines, which provide health benefits, with the private interests of the health care industry in obtaining commercial benefits. Implicit within this narrative is an understanding that regulators supporting private interests with the creation of statutory privileges breach public trust if the regulator is unable to demonstrate they have also safeguarded public interests.

Dutfield's paper adds to Newdick's contribution in identifying that regulators are trusted not only to ensure fairness in the distribution of benefits, but also in ensuring that benefits to private interests yield public health care benefits. Warren-Jones' paper adopts a tangential context to Dutfield's paper in assessing a more general expansion of private commercial rights over health innovation, but identifies that the public interest transcends ethical claims to interests and affixes to commercial interests in sustainable health care markets. Consequently, Warren-Jones argues that innovation regulators are breaching public trust in failing to vouch for the credibility of health care products, the quality of which the public cannot establish for themselves. Alceste Santuari considers how competing private industry interests (exemplified through pharmacies) must be resolved in the public interest. As such his paper recognises a duty on regulators to ensure health care provision is responsive to ensuring adequate supplies are not achieved at the cost of more expensive medicines and this requires innovative approaches to organising medicines market outlets.

As such each of these authors identify a more rounded understanding of regulation that does not conform to a traditional conception of regulators being required to balance seemingly competing interests strictly divided between public and private concerns, or to confine ethical benefits to normative intentions in favour of the actual pursuit of economic gains. Instead, public trust casts regulators as guardians of fairness in the division of benefits, and supporting private interests towards achieving both public and private benefits irrespective of whether the focus is upon ethical imperatives or commercial markets.

Having challenged the existing literature on strict separation between public and private interests, as well as ethical and economic consideration, the convergence of papers identifies how essential the sustainability of behaviours is in future-proofing regulation. For Newdick, sustainability is both an ethical and a budgetary issue in which individual and corporate indulgences today cannot be justified or economically accounted against future increases in both social and commercial costs. For Warren-Jones, the sustainability of health care markets fails if the public interest in receiving good quality products and treatments is identified as a sham because regulators have failed to ensure that quality. This is argued to be far more likely a cause of absolute market failure, because the public have a far lower tolerance for receiving poor quality goods than industry has for reductions in 
profit before deciding to disengage from the market entirely. For Santuari, the sustainability of market-level health care services which are provided through both public and private outlets rests on securing both commercial and public interests. This necessitates an understanding that accreditation linked to population criteria risks private suppliers gravitating to profit maximising markets, leaving public suppliers with the financial losses attendant to meeting demand elsewhere and crowding out the public interest. Instead, an innovative approach to supply structures is advocated, revolving around the quality and quantity of service provision in order to maximise the benefits arising from public and competing private outlets. Overall, these three papers identify that, irrespective of the context being considered, the sustainability of health care provision rests upon amalgamating public and private interests in such a way as to ensure mutual benefits. The regulator is therefore key to achieving and continually reviewing this amalgam, to accommodate the recognition that - while private interests may remain statically focused on cost-efficiency and profit - both markets and public interests change over time.

The value identified in reading across contributions to seemingly divergent debates is that it yields a more comprehensive appreciation of issues and a richer exploration of comparative contexts. This journal issue pushes existing debates about the nature of regulation forward to consider how both public and private interests can be secured, not in competition as mutually exclusive alternatives, but perceived from a perspective which transcends theoretical divides and recognises the value of inclusion. Crucially, this means that pivotal issues such as the role of individual consent need to be reviewed across all contexts to achieve an approach which recognised the value of individual autonomy, as well as the value of medical expertise and a range of other perspectives in reaching the best outcome. An additional gain from this convergence of papers is in identifying that public trust in health care regulation is a recurrent sub-text, which highlights very different expectations of what regulators are expected to achieve. Similarly, the combination of these papers challenge existing divides in interests-based literature to identify a new concern, that of the sustainability of health care provision and regulatory practices. After all, getting everyone involved in working towards benefit sharing must be an endeavour which is mindful of its future, both in terms of the implications of decisions made today and of aspirations in reaching for tomorrow.

\section{References}

Ayres, I. and J. Braithwaite (1991), 'Tripartism: regulatory capture and empowerment', Law \& Social Inquiry, 16(3): 435.

Becker, G. (1986), 'The public interest hypothesis revisited: a new test of Peltzman's theory of regulation', Public Choice, 49: 223-234.

Bernstein, M. (1955), Regulating Business by Independent Commission, Princeton, NJ: Princeton University Press. 
Brownsword, R. and M. Goodwin (2012), Law and the Technologies of the Twenty-First Century, Cambridge, MA: Cambridge University Press.

Busfield, J. (2010), 'A pill for every ill: explaining the expansion of medicine use', Social Science \& Medicine, 70: 934-941.

Carpenter, D. and D. A. Moss (eds) (2014), Preventing Regulatory Capture: Special Interest Influence and How to Limit it, Cambridge, MA: Cambridge University Press.

Davis, C. and J. Abraham (2013), Unhealthy Pharmaceutical Regulation: Innovation, Politics and Promissory Science, London: Palgrave Macmillan.

Donahue, J. and R. Zeckhauser (2011), Collaborative Governance: Private Roles for Turbulent Times, Princeton, NJ: Princeton University Press.

Drahos, P. (2004), 'Intellectual property and pharmaceutical markets: a nodal governance approach', Temple Law Review, 77(2): 401-424.

European Commission (2005), 'Proposal for a Regulation on Advanced Therapies Medicinal Products', SEC (2005) 1444, http://eur-lex.europa.eu/legal-content/EN/TXT/?uri= CELEX:52005PC0567 [January 2017].

European Commission (2008), 'Safe, Innovative and Accessible Medicines: A Renewed Vision of the Pharmaceutical Sector', $\operatorname{COM(2008)~} 666$ final, pp. 4, 14-15, http://ec.europa.eu/ health/human-use/package_en.htm [January 2017].

Feintuck, M. (2004), 'The Public Interest' in Regulation, Oxford: Oxford University Press.

Gutmann, A. and D. Thompson (2004), Why Deliberative Democracy?, Princeton, NJ: Princeton University Press.

Hantke-Domas, M. (2003), 'The public interest theory of regulation: non-existence or misinterpretation?', European Journal of Law and Economics, 15: 165.

Jackson, E. (2012), Law and the Regulation of Medicines, Oxford: Hart Publishing.

Kaye, J., E. A. Whitley, M. Morrison, H. Teare and K. Melham (2015), 'Dynamic consent: a patient interface for the twenty-first century research networks', European Journal of Human Genetics, 23: 141-146.

Lewis, G. and J. Abraham (2001), 'The creation of neo-liberal corporate bias in transnational medicines control: the industrial shaping and interest dynamics of the European regulatory state', European Journal of Political Research, 39(1): 53-80.

Ogus, A. I. (2004), Regulation: Legal Form and Economic Theory, Oxford: Hart Publishing.

Peltzman, S. (1976), 'Toward a more general theory of regulation', The Journal of Law and Economics, 19: 211-240.

Peltzman, S. (1984), 'Constituent interest and congressional voting', The Journal of Law and Economics, 27: 181-210.

Posner, R. A. (1974), 'Theories of economic regulation', Bell Journal of Economics and Management Science, 5: 335-358.

Prosser, T. (2006), 'Public interest and social solidarity', Journal of Law and Society, 33(3): 364.

Sirianni, C. (2009), Investing in Democracy: Engaging Citizens in Collaborative Governance, Washington, DC: Brookings Institute.

Sorauf, F. J. (1957), 'The public interest reconsidered', The Journal of Politics, 19(4): 616-639.

Stigler, G. J. (1971), 'The theory of economic regulation', Bell Journal of Economics o Management Science, 2: 3.

Warren-Jones, A. (2016), 'Regulatory Justifications', Law, Innovation and Technology, 8: 61-99. 